\title{
Third-Party Logistics Company Supplier Evaluation using Analytical Hierarchy Process Method: A Case Study in the Manufacturing Industry
}

\author{
Hamdani Aris Sudrajat ${ }^{1}$, Dewa Gede Angga Paramartha ${ }^{2}$ and Humiras Hardi Purba ${ }^{3}$
}

\author{
Master of Industrial Engineering Program ${ }^{1,2,3}$
}

Mercu Buana University

Jakarta 10510

Indonesia

\begin{abstract}
The need for suppliers who have good quality is a very important problem for both manufacturing organizations and organizations engaged in the service sector. Purchasing function is also vital in determining the profitability and survival of business organizations. Changes in customer demand, improvements in performance, shorter product life cycles and price competition are a form of dynamic environmental challenges. This journal aims to evaluate the performance of tire suppliers for the company's operational vehicles using several criteria. The more criteria the company wants to evaluate its suppliers the more complicated the problems will get, therefore a decision-making technique is needed in selecting suppliers. One method used in decision making is the Analytical Hierarchy Process (AHP). AHP is used because the concept is simple, easy to understand, and has the ability to measure related performance from supplier alternatives in a simple mathematical form. Using 4 criteria, the criteria are price, quality, delivery time, and service. Data processing result using AHP quality has the most important weight with a value of 1,318, followed by price and delivery time with weight 0.975 and last service with weight 0.934 . After analyzing the priority criteria and supplier weights, it can be seen in table 3 that Supplier A has the best performance with a value of 4,594 compared. Supplier D's second order with a value of 4,385, followed by Supplier B has a performance value of 4,158, and Supplier who has the lowest Supplier C performance value has a performance value of 4,106.
\end{abstract}

Key Words: Analytic Hierarchy Proces, Price, Quality, Delivery Time, Service.

\section{INTRODUCTION}

Suppliers who have good quality are needed today. Competition between one organization and another is getting tighter in maintaining its customers. The need for suppliers who have good quality is a very important problem for both manufacturing organizations and organizations engaged in the service sector. The price of goods supplied by the supplier is also a consideration because of the impact that can affect the cost of a product. The importance of selecting suppliers encourages an organization to review their purchasing strategies. Since the purchasing function has become vital in determining the profitability and survival of business organizations, it has been receiving considerable attention [1].

Purchasing function is also vital in determining the profitability and survival of business organizations. Supplier selection decisions is a necessity for an organization because a successful purchasing decision directly depends on selecting the "right" vendor and in order to achieve that an organization needs to rethink their purchasing and evaluation strategies. As business organizations become more dynamics in the last ten years, then the theory related to decision making continues to grow and its implementation is in various fields of the management system [2]. In decision-making also occasionally requires supporting tools. The selection of an efficient vendor is an important process or even the key to the purchasing function because the selection of the right vendor will provide significant savings to the organization. Vendor selection is crucial because of its strategic importance especially when it comes to Government Supplies where money \& quantities involved are generally very large. Usually, the most important measure of a supplier's service is his record of past performance [3]. Establishing positive partner relationships with suppliers is certainly one of the many things that need to be pursued. By strengthening the relationship between the contractor and the supplier through this partnership, it is expected that if there is a change in scheduling or the volume of material purchased, the 
overall project completion target will not be disrupted [2]. Changes in customer demand, improvements in performance, shorter product life cycles and price competition are a form of dynamic environmental challenges. Supplier selection is one area that can provide advantages to get the market because, with supplier selection, operational effectiveness will increase as well as strategic relationships between organizations [4]. Supplier selection problem is affected by different tangible and intangible criteria such as quality, price, delivery, technical capability and many more. So selecting the right supplier for a decision maker to reduce purchasing cost improves competitive ability and increase customer satisfaction [5]. Factors from external and internal influences were considered to meet the needs of markets within the global changing environment. [6]

This journal aims to evaluate the performance of tire suppliers for the company's operational vehicles using several criteria. When evaluating the criteria, trade-offs often occur such as the presence of suppliers that offer good quality products, but with uncertain delivery time [4]. The more criteria the company wants to evaluate its suppliers the more complicated the problems get, therefore a decision-making technique is needed in selecting suppliers. One method used in decision making is Analytic Hierarchy Proces (AHP). This technique is a method used in the decision-making process of a complex problem with aspects or criteria that are considered quite a lot [7]. AHP and their integrated methods are most preferred among researchers. Integration of AHP with other methods is very often where authors using AHP for determination criteria weights and other for evaluation [8]. AHP is used because the concept is simple, easy to understand, and has the ability to measure related performance from supplier alternatives in a simple mathematical form.

\section{LITERATURE REVIEW}

Analytical Hierarchy Process (AHP) was developed by Thomas L. Saaty in 1988. When several criteria must be considered, AHP is one of many methods that will help to prioritize several alternatives. It also constructs complex problems into a hierarchy for the decision makers. AHP is used for problems solving in terms of planning, alternative determination, prioritization, policy selection, resource allocation, needs determination, results in forecasting, outcome planning, system planning, performance measurement, optimization, and conflict resolution [2,9]. The structuring complexity of AHP model is based on an idea that complex problems should be presented in such a way that even people without formal training could understand it [9]. There are 4 Basic principles in the AHP methodology for decision-making, namely: Decomposition, Comparative Judgement, Synthesis of Priority and Logical Consistency. In using those four principles, AHP brings together two aspects of decision making:

a. Qualitatively, the AHP identify and the problems and assessments, in order to find the problem solutions, and

b. Quantitatively, the AHP performs numerical comparisons and assessments in order to find the problem solutions.

Thomas L. Saaty stated four different priorities when performing analysis based on the analytical hierarchy process, there are: [9]

1. Define the problem and determine the kind of knowledge sought.

2. Structure the decision hierarchy from the top with the goal of the decision, then the objectives from a broad perspective, through the intermediate levels (criteria on which subsequent elements depend) to the lowest level (which usually is a set of the alternatives).

3. Construct a set of pairwise comparison matrices. Each element in an upper level is used to compare the elements in the level immediately below with respect to it.

4. Use the priorities obtained from the comparisons to weigh the priorities in the level immediately below. Do this for every element. Then for each element in the level below add its weighed values and obtain its overall or global priority. Continue this process of weighing and adding until the final priorities of the alternatives in the bottom most level are obtained [7].

AHP is a principle of measurement through pair-wise comparisons and relies on the judgment of experts to acquire priority scales which measure insubstantial elements in relative terms. AHP methods construct the decision process into a hierarchy and the decision making involves choosing an option from different alternatives. AHP judges and selects elements/concepts which have a greater influence on a preset objective [10]. In order to create and increase competitive advantages, it is very important for a company to evaluate its business partner/supplier. In difficult economic situations, right supplier management has an important influence on companies and their future business. Analytical Hierarchy Process (AHP) can be used to support the decision makers suppliers that best suits their needs and problem. AHP reflects a structured workflow to deal with complex decisions by offering a rational framework for solving complex problems. AHP provides a well-founded and comprehensible solution which makes decisions credible especially in teams or groups decision making. AHP and information technologies combined can minimize common pitfalls of team decisions in an organization. It is also more effective and avoids the lack of focus as well as subjective decisions [11]. AHP is a "systematic rationality" process, furthermore, AHP enables to consider a problem as a whole and evaluate the simultaneous interactions of various components arranged in a hierarchical manner so that they are easily understood and analyzed. AHP also can be used to stimulate an emergence of ideas to carry out creative actions, and to evaluate the effectiveness of the action, to help leaders determine what information should be gathered to evaluate the influence of relevant 
factors in complex situations, track inconsistencies in participants' considerations and preferences, so that leaders are able to assess the quality of knowledge of their assistants and stabilize the solution [12]

There are 5 stages of supplier selection using the AHP method [13] which are:

1. Identify the criteria to be used in supplier selection.

2. Make a pairwise comparison of the relative importance of the criteria to the goal, and calculate the priority or weighting criteria based on the information obtained.

3. Measure / assess suppliers in meeting the criteria.

4. Using the information in step 3, make a comparison of the relative importance of the supplier/supplier against the criteria, and calculate the priority.

5. Use the results in steps 2 and 4, then calculate the priority or the weight of the supplier for the purpose of the hierarchy.

The practical use of AHP is presented with an extended business example of Henkel in Germany. AHP assures objective results in team decisions which lead to the right business partner and minimizes the distress of pitfalls in a success-critical decision process. Therefore, AHP represents a compatible process in supplier evaluation and give the decision-maker assurance of a clear, objective and comprehensible evaluation. [11] demonstrates the structured approach of AHP. AHP used as a tool in supplier evaluation to identify best-in-class suppliers and build a ranking by its criterion's weight and the degree of performance. The standardization of team decisions of stakeholders represents the advantage of the proposed method. The selection of best-in-class suppliers is switched from a subjective decision of an individual to an objective team decision by establishing a hierarchy and defining criteria, of all involved parties. There's also drawbacks as well. When a new potential supplier is included in the system, the evaluation has to be start all over again and development and evaluation of pair-wise comparisons and illustration of the results are very time without AHP software. Research [1], proposes an AHP approach for the selection of vendors in a supply chain. A systematic approach using AHP approach has been applied for vendor selection. It can be concluded that the model could facilitate decision making. The approach could help in reducing time consuming efforts in the vendor selection process. Not only can the model make tradeoffs between both qualitative and quantitative factors, but it also enables decision-makers to deal with inconsistent judgments systematically. The pair-wise comparison procedure is able to capture relative judgments of two elements at one time in a trustworthy manner and ensure consistency of these values. According to [1] involves a decision making team consist of experts from the industry side which are purchasing head, purchasing manager, sales manager, product manager, quality manager and production in-charge. Attributes and sub-attributes needed in vendor selection have been chosen through questionnaire survey. Respondents are selected randomly from different functional areas of the company who directly involved with the material/components. According to [2] research regarding Supplier Performance Assessment using AHP, conducted in Hyundai Alumunium Co., Ltd, the order of criteria that has the most important priority in Hyundai Aluminium is as follows: Quality (0.290), Delivery accuracy (0.279), Price (0.238) and Services (0.193). Quality criteria and delivery accuracy are important points in the work of a project. If the quality of glass from suppliers is not good, can lead to discoloration of glass and can affect the strength of glass. This will affect contractors such as Hyundai Aluminium. Analytical Hierarchy Process is method that are used to select the right supplier. AHP model provide a better way to evaluate the criteria that has been set, depending on its importance [14]. Alsuwehri also use a multi-criteria decision model with the proposed AHP model by scoring the performance of suppliers. The results show the models are able to assist decision-makers to examine the strengths and weaknesses of supplier selection by comparing them with appropriate criteria, sub-criteria and sub sub-criteria. While in two last years few researcher use new method (BestWorst method) of using ingtegrated AHP [15].

\section{METHODOLOGY}

AHP method requires assessment using expert respondents (experts), therefore this study chose a respondent who is considered an expert in the field of truck tire supplier evaluation. What is meant by expert respondents here are people who are experienced in the field of supplier performance evaluation, one of which is in the procurement of tires. In the selection criteria for this evaluation model, data collection and processing are done in 2 stages:

1. The collection of criteria that will be given to respondents is collected based on several previous research references. Then the selection of criteria is carried out through interviews in determining the appropriate criteria for evaluating truck tire suppliers.

2. Weighting the tire supplier evaluation criteria according to respondents through a questionnaire which is then asked to give weight to the criteria with the basis of pairwise comparison [7]. 


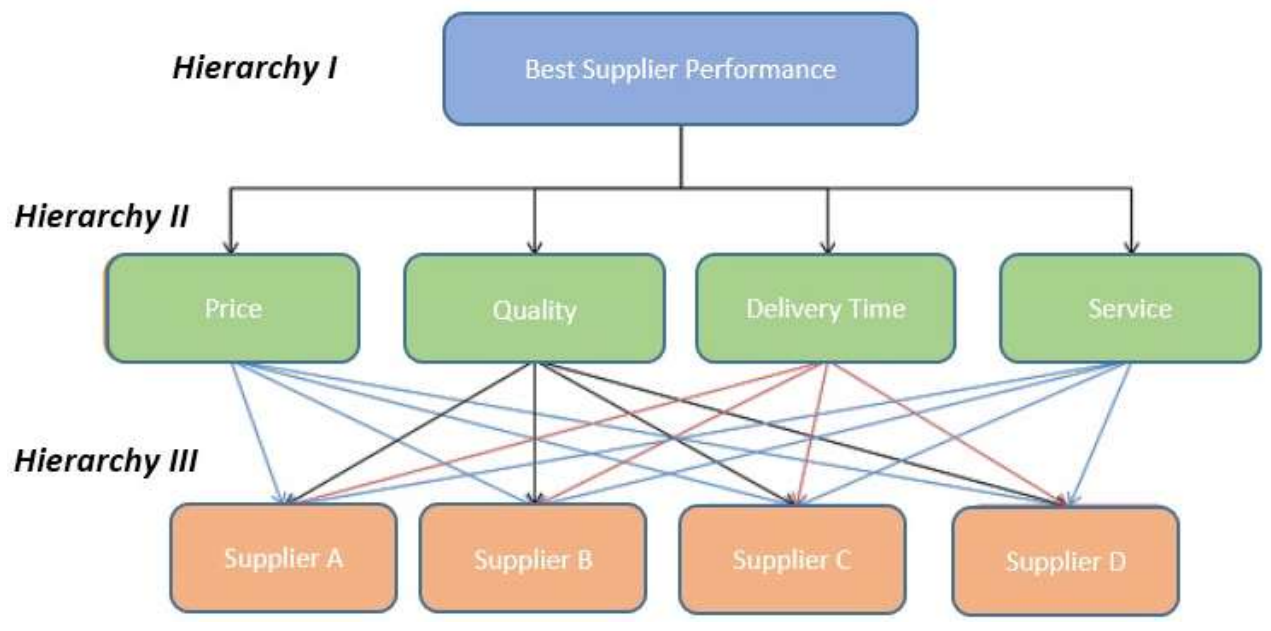

Figure 1. AHP Hierarchy.

The data processing stage is done by summing the weight given by the respondents to the criteria according to the basic pairwise comparison scale [7]. The following are the criteria selected by the respondents in determining the weight of criteria to evaluate supplier performance.

Table 1. Truck Tires Supplier Evaluation Criteria

\begin{tabular}{|c|c|}
\hline No. & Criteria \\
\hline 1 & Price \\
\hline 2 & Quality \\
\hline 3 & Delivery Time \\
\hline 4 & Service \\
\hline
\end{tabular}

Data Processing with AHP Method

Data processing is carried out in 2 stages:

1. Processing data from respondents using Excel, with assessments obtained from respondents for each criterion.

2. Calculate the weight which is a priority for each criterion and the inconsistency ratio using Excel.

The comparison matrix of criteria for respondents is input for processing data using Excel. The results of data processing using Excel are the weights and priorities of each criterion and the inconsistency ratio of each pairwise comparison matrix.

\section{RESULT AND DISCUSSION}

\subsection{Hierarchy Structure Determination}

This study uses the AHP method to measure supplier performance, for the tire supplier category in third-party logistics companies. As for measuring supplier performance, there are certain criteria. The AHP method has 3 levels, the first level is to measure supplier performance, the second level is the criteria, the third level is the alternative supplier. The first stage in this study is determining criteria through literature studies. The second stage is an interview with respondents who are experts in its field. After determining the criteria, a questionnaire was made to assess the level of importance of each of these criteria.

\subsection{Criteria Weighting and Consistency Test}

Based on the results of the questionnaire data processing, it is known that the priority weights of each criterion will be analyzed in this chapter. This questionnaire was filled in by the expert, then the results of the questionnaire were tested for consistency on all criteria. Test consistency on the criteria shows that this questionnaire is filled consistently. After the consistency test gives consistent results, so the weighting process can be carried out for suppliers, the results of which can be seen in Figure 2. 


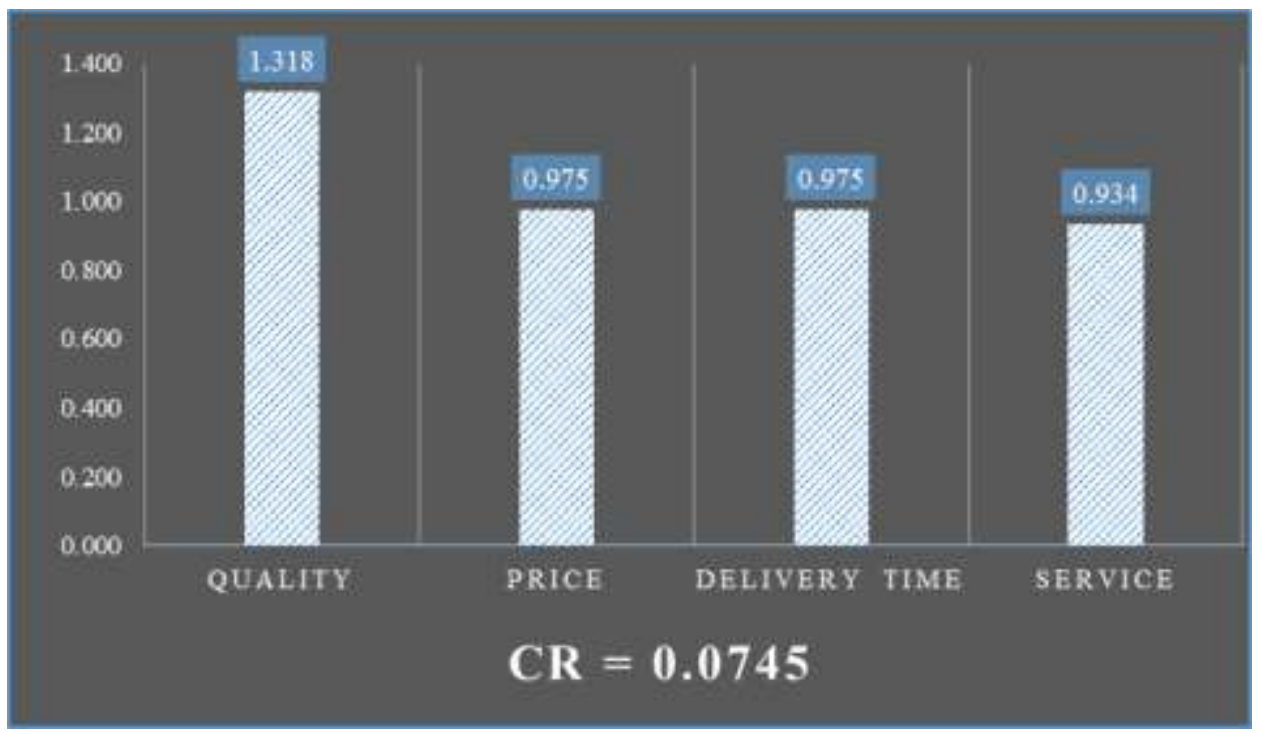

Figure 2. Weight and Ratio of Criteria Inconsistency

In Figure 1 it can be seen that quality is the most important thing because it has the highest value of 1.318 . Because in carrying heavy loads requires a quality tire to minimize the risk of safety and delays in shipping. Prices and delivery times become the second priority with a value of 0.975 due to the company's economic factors. then followed by supplier service with a value of 0.934 .

\subsection{Consistency Test and Supplier Weighting on Quality}

After analyzing the priority weights of the criteria, the following will be analyzed the Supplier priority weighting on the quality criteria as shown in Figure 3 below.

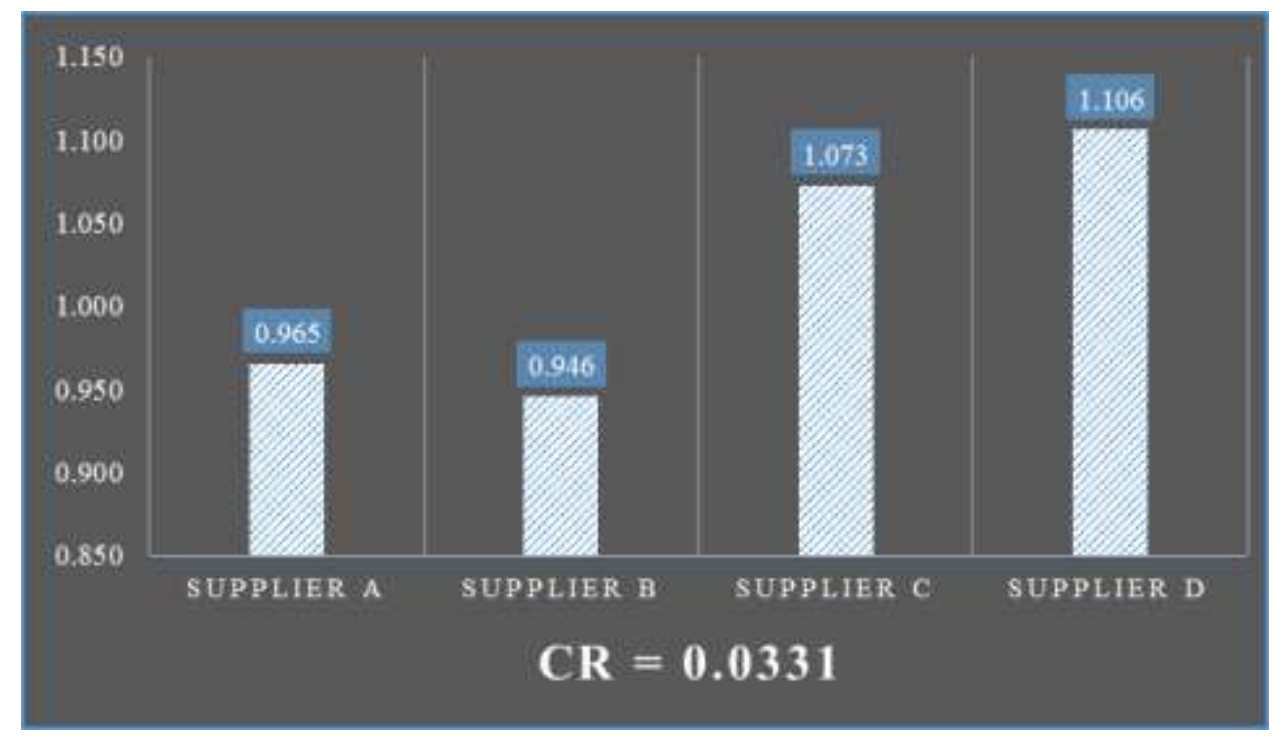

Figure 3. Supplier Weight on Quality Criteria

Suppliers who have the highest value for quality criteria are Supplier D with a value of 1.106, followed by supplier C with a value of 1.073 , supplier A with a value of 0.965 , and finally supplier B with a value of 0.946 . Supplier D has the best tire quality by supplying tires that have the longest service life.

\subsection{Consistency Test and Supplier Weighting on Price}

After analyzing the priority weight of the criteria, the following will be analyzed by the Supplier priority weight on the price criteria as shown in Figure 4 below. 
International Journal of Advances in Scientific Research and Engineering (ijasre), Vol 5 (1), January-2019

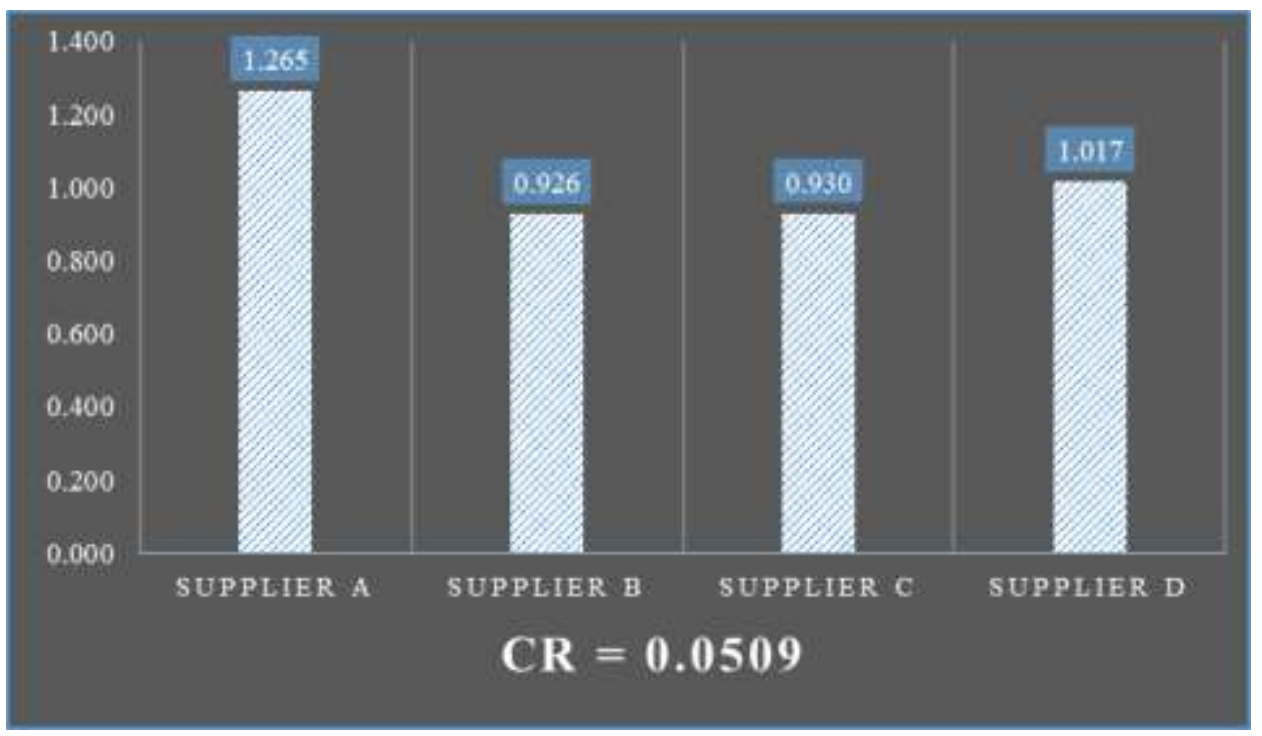

Figure 4. Supplier Weight on Price Criteria

The supplier who has the highest value for the price criteria is Supplier A with a value of 1,265, this shows that supplier A is able to provide the lowest price compared to other suppliers. The second position was Supplier D with a value of 1,017, then supplier C with a weight of 0.93 , and supplier B 0.926.

\subsection{Consistency Test and Supplier Weighting on Delivery Time}

After analyzing the priority weight of the criteria, the following will be analyzed the Supplier priority weights on the delivery time criteria as shown in Figure 5 below.

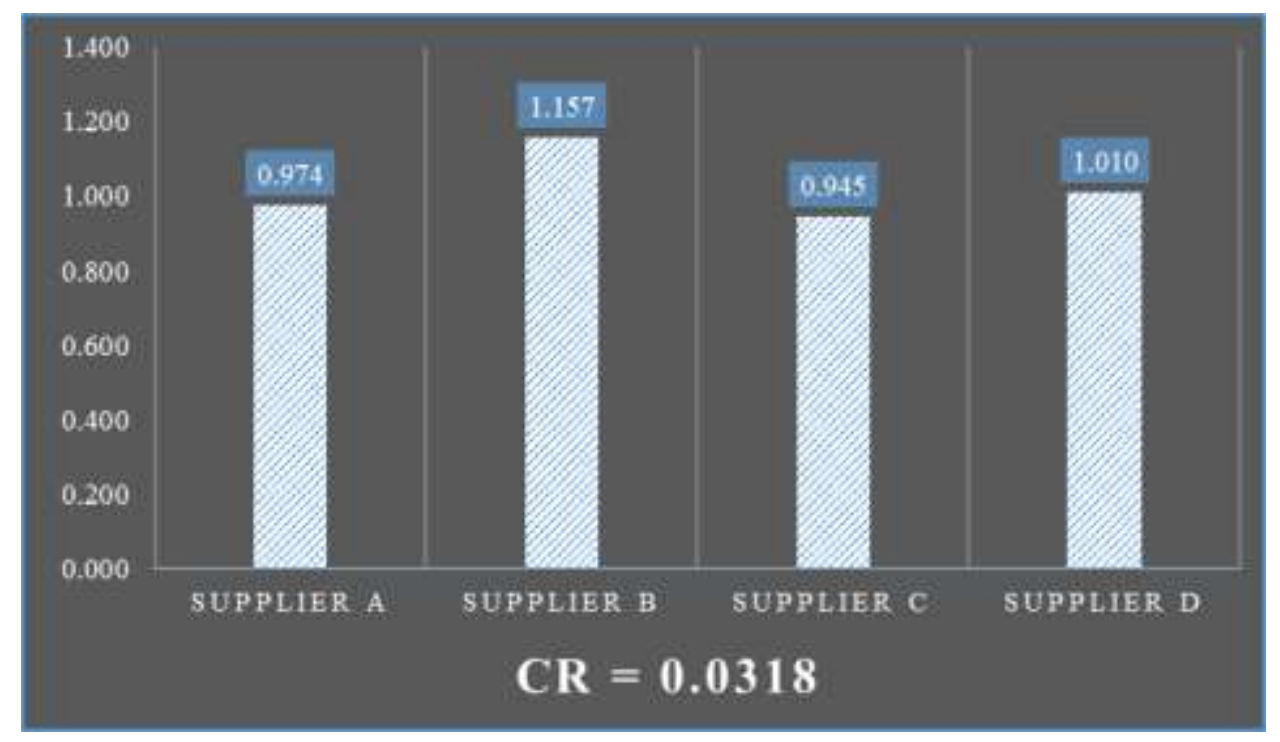

Figure 5. Supplier Weight on Delivery Time Criteria

The supplier who has the highest value for the shipping time criteria is Supplier B with a weight of 1.157, this indicates that supplier B is capable of supplying tires with the fastest time. Second-placed supplier D with a value of 1.010, all three suppliers A with a value of 0.974 , and finally supplier $\mathrm{C}$ with a value of 0.945 .

\subsection{Consistency Test and Supplier Weighting on Service}

After analyzing the priority weight of the criteria, the following will be analyzed the Supplier priority weighting on the service criteria as shown in Figure 6 below. 
International Journal of Advances in Scientific Research and Engineering (ijasre), Vol 5 (1), January-2019

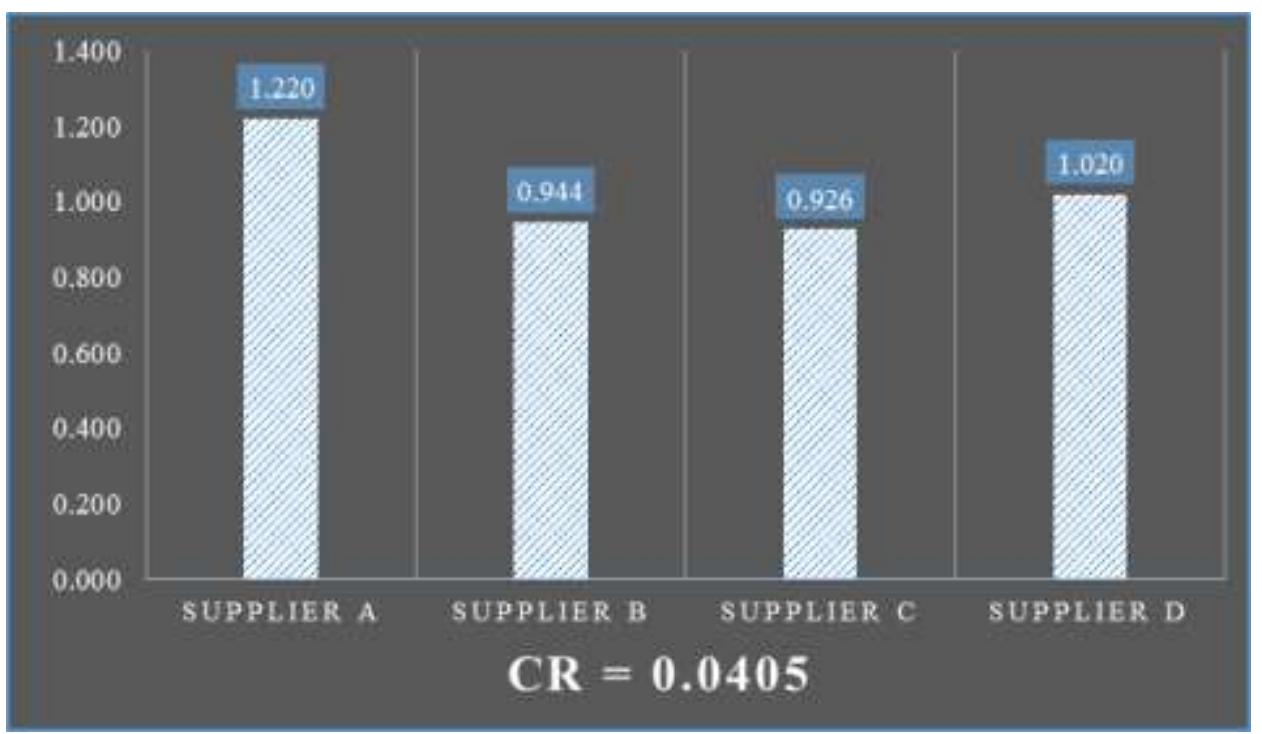

Figure 6. Supplier Weight on Service Criteria

The supplier who has the highest value for the best service criteria is supplier A with a value of 1,220 , this shows that supplier A is the supplier with the best service. Supplier D has a value of 1,020, second. For the third order of this criterion is Supplier B, and all four suppliers $\mathrm{C}$ with a value of 0.926 .

\subsection{Supplier Priority Weight}

The following will be analyzed the final weight of Supplier priority on each criterion as in Table 3 below.

Table 2. Weighting Final Result Priority Supplier

\begin{tabular}{|c|c|c|}
\hline Alternative & Weigh & Rank \\
\hline Supplier A & 4,594 & 1 \\
\hline Supplier B & 4,158 & 3 \\
\hline Supplier C & 4,106 & 4 \\
\hline Supplier D & 4,385 & 2 \\
\hline
\end{tabular}

After analyzing the priority criteria and supplier weights, it can be seen in table 2 that Supplier A has the best performance with a value of 4,594 compared. Supplier D's second order with a value of 4,385, followed by Supplier B has a performance value of 4,158 , and Supplier who has the lowest Supplier C performance value has a performance value of 4,106. This criterion can be taken into consideration in choosing tire suppliers in third-party logistics companies.

\section{CONCLUSIONS AND RECOMMENDATIONS}

\subsection{Conclusions}

This study aims to make modeling in tire supplier selection based on performance evaluation with the AHP method. Based on these objectives, the conclusion that can be drawn is that there are 4 priority criteria for evaluating suppliers. The AHP method gives a different order of priority:

1. From the results of calculated in Excel, the quality criteria are the most important criteria, followed by the price and delivery time with the same weight. And the last consideration is the level of supplier service.

2. Supplier A was selected as the best performing supplier, followed by second supplier D, supplier B ranked third, and supplier with the lowest performance was supplier C. 


\subsection{Recommendations}

1. More criteria and sub-criteria can be added for tire supplier evaluation/selection

2. This research can be developed with other multi-criteria method

3. An application program can be design to support the tire supplier evaluation/selection support systems.

\section{REFERENCES}

[1] Jayant, A., Singh, A., \& Patel, V. (2011). “An AHP Based Approach for Supplier Evaluation and Selection in Supply Chain Management." International Journal of Advanced Manufacturing Systems, 2(1), 1-6.

[2] Santoso, D., Besral, A. M., \& Buana, U. M. (2018). "Supplier Performance Assesment Using Analytical Hierarchy Process Method." Sinergi, 22(1), 37-44.

[3] John, K., Baby, V. Y., \& Mangalathu G. S. (2013). "Vendor Evaluation and Rating Using Analytical Hierarchy Process." IJESIT, vol. 2, pp.447-455.

[4] Agarwal, P., Sahai, M., Mishra, V., Bag, M., \& Singh, V. (2014). "Supplier Selection in Dynamic Environment using Analytic Hierarchy Process.” International Journal of Information Engineering and Electronic Business, 6(4), 20-26.

[5] Verma, D. S., and Pateriya, Ajitabh. (2013). "Supplier Selection Through Analytical Hierarchy Process : A Case Study In Small Scale Manufacturing Organization.” IJETT, vol. 4, pp. 1428-1433.

[6] Özkan, B., Basligil, H., and Sahin, N. (2011). "Supplier Selection Using Analytic Hierarchy Process : An Application From Turkey." Proceedings of the World Congress on Engineering, vol. 2.

[7] Saaty, T. L. (1980). The Analytic Hierarchy Process. McGraw-Hill, New York, 579-606.

[8] Mukherjee, K. (2016). "Supplier selection criteria and methods: past, present and future." International Journal of Operational Research, 27(1-2), 356-373.

[9] Bogdanoff, M. J. (2009). Supplier Evaluation Using Analytical Hierarchy Process.

[10] Malik, M. M., Abdallah, S., \& Hussain, M. (2015). “Assessing supplier environmental performance: Applying Analytical Hierarchical Process in the United Arab Emirates healthcare chain.” Renewable and Sustainable Energy Reviews, 55, 1313-1321. https://doi.org/10.1016/j.rser.2015.05.004

[11] Politis, S., Klumpp, M., \& Celebi, D. (2010). “Analytical Hierarchy Process in Supplier Evaluation.” 16th International Working Seminar on Production Economics, Conference Proceedings, 3(January 2010), 411-424.

[12] Rimantho, D., Fathurohman, F., Cahyadi, B., \& Sodikun, S. (2017). "Pemilihan Supplier Rubber Parts Dengan Metode Analytical Hierarchy Process Di PT.XYZ.” Jurnal Rekayasa Sistem Industri, 6(2), 93. https://doi.org/10.26593/jrsi.v6i2.2094.93-104

[13] Nydick, R. L., \& Hill, R. P. (1992). "Using the Analytic Hierarchy Process to Structure the Supplier Selection Procedure.” International Journal of Purchasing and Materials Management, 28(2), 31-36.

[14] Alsuwehri, Y. (2011). Supplier Evaluation and Selection by Using The Analytic Hierarchy Process Approach, 1-37.

[15] Rezaei, J. (2015). "Best-worst multi-criteria decision-making method." Omega, 53, 49-57. 